\title{
Distal Tubule Bicarbonate Accumulation In Vivo Effect of Flow and Transtubular Bicarbonate Gradients
}

Michelle lacovitti, $¥$ Lorena Nash, $¥$ Linda N. Peterson, $\$ \$$ James Rochon, $¥$ and David Z. Levine* $¥$ Departments of ${ }^{*}$ Medicine, $¥$ Physiology, and §Pediatrics, University of Ottawa and the Ottawa General Hospital, Ottawa, Ontario, Canada

\begin{abstract}
We have performed microperfusion studies on distal tubules of normal and alkalotic rats in an attempt to demonstrate in vivo bicarbonate secretion. All perfusion solutions were free of phosphate and other nonbicarbonate buffers. In both normal and alkalotic rats, distal perfusions elicited significant $\mathrm{CCO}_{2}$ entry only at high flow ( $24 \mathrm{nl} / \mathrm{min})$. Even when perfusate $\mathrm{CCO}_{2}$ concentration closely matched plasma $\mathrm{tCO}_{2}$ concentration $\left(30 \mathrm{mM} \mathrm{tCO}_{2}\right)$, significant $\mathrm{tCO}_{2}$ entry again occurred at high flow. This was associated with a rise of the perfusate $\mathrm{CO}_{2}$ concentration, which indicated net entry of $\mathrm{CCO}_{2}$ against a concentration gradient. In this "symmetrical" perfusion situation, acetazolamide blockade prevented $\mathrm{tCO}_{2}$ entry. Accordingly: (a) distal tubule $\mathrm{tCO}_{2}$ entry is demonstrable in both alkalotic and normal rats at high flow rates; (b) increasing perfusate $\mathrm{tCO}_{2}$ concentration can suppress tCO $\mathrm{CO}_{2}$ entry; and (c) entry can occur in the absence of a gradient and this effect can be blocked by acetazolamide.
\end{abstract}

\section{Introduction}

In 1977, McKinney and Burg demonstrated that cortical collecting ducts taken from alkalotic rabbits secreted bicarbonate in vitro (1). They also showed subsequently (2) that the rate of secretion could be enhanced by amiloride and inhibited by acetazolamide. Subsequently, others have confirmed the existence of collecting duct bicarbonate secretion in vitro and further, have shown that the transtubular chloride gradient can modulate this process (3).

In the present studies, we undertook to demonstrate distal tubule bicarbonate secretion ${ }^{1}$ in vivo by means of microperfusion experiments on alkalotic rats, normal rats, and rats subjected to amiloride and acetazolamide treatment. We recognize in these experiments that the distal tubule accessible to in vivo microperfusion is composed of a very heterogeneous epithelial cell population (4). The first experiments, carried out in alkalotic rats, show that at high flow, net $\mathrm{tCO}_{2}$ accumulation can be demonstrated but is not modulated by reversal of the chloride gradient. In normal animals, high flow stimulates $\mathrm{tCO}_{2}$ accumu-

Address correspondence to Dr. Levine, Department of Medicine, Health Sciences Building, 451 Smyth Road, Ottawa, Ontario, Canada K1H 8M5. A portion of this work has already appeared in abstract form (1985, Clin. Res., 33:487A).

Received for publication 29 October 1985 and in revised form 20 June 1986.

1. In this paper $\mathrm{tCO}_{2}$ accumulation, $\mathrm{HCO}_{3}$ accumulation, and negative values for $\mathrm{JtCO}_{2}$ are used interchangeably.

J. Clin. Invest.

(c) The American Society for Clinical Investigation, Inc.

$0021-9738 / 86 / 12 / 1658 / 08 \quad \$ 1.00$

Volume 78, December 1986, 1658-1665 lation even when perfusate concentration rises above that of plasma due to net addition of $\mathrm{tCO}_{2}$. Nevertheless, as the initial perfusate $\mathrm{tCO}_{2}$ concentration is increased, $\mathrm{tCO}_{2}$ accumulation is suppressed. Finally, we show that acetazolamide treatment can inhibit flow-stimulated $\mathrm{tCO}_{2}$ accumulation. Assuming there is no net intraluminal generation of bicarbonate, these results are consistent with a bicarbonate secretory effect.

\section{Methods}

These studies were performed on male Sprague Dawley rats, weighing $\sim 300 \mathrm{~g}$, bred and raised in a climate-controlled facility at the University of Ottawa. The animals were allowed free access to water and food (rat chow 5012; Ralston Purina of Canada Ltd., Whitby, Ontario) until the time of experimentation. The rats were anesthetized with $100 \mathrm{mg} / \mathrm{kg}$ Inactin (BYK Gulden, Konstanz, Federal Republic of Germany) and prepared for micropuncture and distal microperfusion as previously described (4). The data were derived from 239 distal tubule samples obtained from 92 rats. Of these, 96 were paired collections at two flow rates, 27 were early distal free-flow collections, and 20 were unpaired collections (see below). In all studies, the sequence of high and low flow perfusions was varied.

Experimental design. It is useful to give an overview of the rationale behind the sequential planning of our experiments. First, bicarbonate secretion was sought in alkalotic animals in view of previous reports (1, 2). Initially, distal tubule perfusions were carried out in alkalotic animals under circumstances where the luminal chloride concentration exceeded that of plasma, presumably facilitating bicarbonate entry (3). Having demonstrated bicarbonate accumulation, we next asked whether this could be attributed to the composition of the perfusate, the alkalotic state of the animals, or the flow rate. Therefore, we perfused distal tubules of alkalotic animals at normal and high flow using a $\mathrm{tCO}_{2}$ concentration of $30 \mathrm{mM}$ and $\mathrm{Na}, \mathrm{K}$, and $\mathrm{Cl}$ designed to simulate free-flow early distal fluid. These values were determined from the analysis of free-flow micropuncture samples. Having shown that $\mathrm{JtCO}_{2}$ was negative only at high flow in alkalotic rats, it next seemed appropriate to study normal animals. The perfusate $\mathrm{tCO}_{2}$ concentrations in three groups of normal animals of 10,27 , and $41 \mathrm{mM}$ were chosen to establish: (a) a favorable plasma to lumen $\mathrm{tCO}_{2}$ gradient, $(b)$ to minimize it, or $(c)$ to reverse it. Because this led to the demonstration that high flow was associated with $\mathrm{tCO}_{2}$ accumulation in the presence of a favorable gradient, we attempted to further examine this effect by use of acetazolamide and amiloride, as well as to assess $\mathrm{tCO}_{2}$ accumulation rates when perfusate $\left[\mathrm{tCO}_{2}\right]$ was rigorously matched with plasma. Thus, perfusion with acetazolamide was undertaken with and without a favorable $\mathrm{tCO}_{2}$ gradient. The subsequent sections describe in detail our experimental procedures on alkalotic rats, normal rats, and acetazolamide-treated rats.

Alkalotic rats. Using the protocol of Galla et al. (5), 38 animals were subject to chloride depletion by acute peritoneal dialysis while being infused with Plasmanate (Cutter Laboratories, Inc., Berkeley, CA) (2\% of the body weight) to maintain hematocrit at predialysis levels. Thereafter, they were infused with an isometric solution designed to match the plasma values. All other aspects of the preparation for micropuncture, manufacture of perfusion pipettes, calibration of microperfusion pumps, etc., have been recently detailed (4).

Normal rats. 37 normal rats were infused with donor plasma $(0.5 \%$ of the body weight) followed by a sustaining infusion of isotonic saline 


\begin{tabular}{|c|c|c|c|c|c|c|c|c|}
\hline Solution & Protocol & $\mathrm{HCO}_{3}$ & $\mathrm{Na}$ & $\mathbf{K}$ & $\mathrm{Cl}$ & $\mathrm{SO}_{4}$ & Gluconate & Urea \\
\hline & & $m M$ & $m M$ & $m M$ & $m M$ & $m M$ & $m M$ & $m M$ \\
\hline 1 & Alkalotic rats, $125 \mathrm{mM} \mathrm{Cl}$ & 25 & 150 & 0 & 125 & 0 & 0 & 0 \\
\hline 2 & Alkalotic rats, $\mathrm{SO}_{4}$ substitution for $\mathrm{Cl}$ & 25 & 150 & 0 & 0 & 62.5 & 0 & 0 \\
\hline 3 & Alkalotic rats, simulated tubular fluid & 32 & 56 & 2 & 26 & 0 & 0 & 22 \\
\hline 4 & Normal rats, perfusate $\left[\mathrm{tCO}_{2}\right]>$ plasma $\left[\mathrm{tCO}_{2}\right]$ & 45 & 69 & 2 & 26 & 0 & 0 & 0 \\
\hline 5 & Normal rats, perfusate $\left[\mathrm{tCO}_{2}\right] \approx$ plasma $\left[\mathrm{tCO}_{2}\right]$ & 28 & 56 & 2 & 26 & 0 & 4 & 22 \\
\hline 6 & Normal rats, perfusate $\left[\mathrm{tCO}_{2}\right]<$ plasma $\left[\mathrm{tCO}_{2}\right]$ & 12 & 56 & 2 & 26 & 0 & 20 & 22 \\
\hline 7 & $\begin{array}{l}\text { As solution } 6+\text { systemic and luminal acetazolamide } \\
\left(10^{-3} \mathrm{M}\right) \text { blockade }\end{array}$ & 12 & 56 & 2 & 26 & 0 & 20 & 22 \\
\hline 8 & As solution $6+$ amiloride $\left(10^{-4} \mathrm{M}\right)$ & 12 & 56 & 2 & 26 & 0 & 20 & 22 \\
\hline 9 & $\begin{array}{l}\text { Normal rats, perfusate directly gassed, perfusate } \\
{\left[\mathrm{tCO}_{2}\right]=\text { plasma }\left[\mathrm{tCO}_{2}\right]}\end{array}$ & 30 & 56 & 2 & 26 & 0 & 2 & 22 \\
\hline 10 & $\begin{array}{l}\text { As solution } 9+\text { systemic and luminal }\left(10^{-3} \mathrm{M}\right) \\
\text { acetazolamide blockade }\end{array}$ & 30 & 56 & 2 & 26 & 0 & 2 & 22 \\
\hline
\end{tabular}

* Actual $\mathrm{Na}$ measured is $6-8 \mathrm{mM}$ higher due to $\mathrm{Na}$ in $0.15 \%$ Lissamine green dye. Actual $\mathrm{tCO}_{2}$ measured is $2-4 \mathrm{mM}$ lower due to titration by acid in $0.15 \%$ Lissamine green dye.

at $1 \%$ of the body weight per hour. An additional five normal rats were dialyzed as described by Galla et al. (5) to provide a control for the dialyzed alkalotic animals. These rats were dialyzed against the control solution (5) and received plasmanate infusions ( $1 \%$ of the body weight) to sustain hematocrit at predialysis level. They were then infused with an isometric solution also as previously described (5).

Acetazolamide-treated rats. 18 rats were subjected to systemic and intraluminal acetazolamide treatment. In all cases $10^{-3} \mathrm{M}$ acetazolamide was added to the perfusate solution (see Table I) and the animals received an intravenous loading dose of $20 \mathrm{mg} / \mathrm{kg}$ acetazolamide followed by a systemic infusion at the rate of $20 \mathrm{mg} / \mathrm{kg}$ per h in a $300 \mathrm{mM} \mathrm{NaHCO}_{3}$ solution. As Table II shows, this protocol resulted in the maintenance of plasma total $\mathrm{CO}_{2}$ concentrations which were not different from control. In this fashion, the transtubular gradient for $\mathrm{tCO}_{2}$ was not altered with respect to control.

Perfusion solutions. Table I lists the 10 perfusion solutions we used. As already indicated at the beginning of Methods, solutions 1 and 2 were designed to reverse the chloride gradient while maintaining a perfusate $\mathrm{tCO}_{2}$ concentration similar to that previously used in distal tubule perfusion studies $(4,6)$. Solution 3 was designed to simulate early distal fluid composition in alkalotic rats under free-flow conditions. To determine this composition, separate experiments were undertaken in eight dialyzed alkalotic rats whereby early distal free-flow collections were undertaken as previously described (7). These samples were analyzed for $\left[{ }^{3} \mathrm{H}\right]$ inulin, $\mathrm{Na}, \mathrm{K}$, and total $\mathrm{CO}_{2}$ concentrations (see below). Thus, ac-

Table II. Blood Values

\begin{tabular}{lccc}
\hline Measurements & $\begin{array}{l}\text { Normal rats } \\
(n=42)\end{array}$ & $\begin{array}{l}\text { Alkalotic rats } \\
(n=38)\end{array}$ & $\begin{array}{l}\text { Acetazolamide- } \\
\text { treated rats } \\
(n=12)\end{array}$ \\
\hline $\mathrm{pH}$ & $7.42 \pm 0.04$ & $7.57 \pm 0.01^{*}$ & $7.32 \pm 0.01^{*}$ \\
$\mathrm{pCO}($ mmHg $)$ & $45.3 \pm 0.59$ & $49.6 \pm 0.60^{*}$ & $57.7 \pm 1.90^{*}$ \\
$\mathrm{tCO}($ meq/liter $)$ & $29.9 \pm 0.19$ & $44.7 \pm 0.38^{*}$ & $30.9 \pm 0.58^{*}$ \\
$\mathrm{Na}($ meq/liter $)$ & $144.8 \pm 0.3$ & $144.0 \pm 0.2^{*}$ & $144.1 \pm 0.5$ \\
$\mathrm{~K}($ meq/liter $)$ & $4.6 \pm 0.1$ & $3.3 \pm 0.04^{*}$ & $3.8 \pm 0.1^{*}$ \\
$\mathrm{Cl}($ meq/liter $)$ & $101.8 \pm 0.5$ & $82.6 \pm 0.5^{*}$ & $101.3 \pm 0.6^{*}$ \\
$\mathrm{Hematocrit}(\%)$ & $45.9 \pm 0.3$ & $45.6 \pm 0.3^{*}$ & $49.0 \pm 1.0^{*}$ \\
Protein $(\mathrm{g} / \mathrm{dl})$ & $5.2 \pm 0.05$ & $6.2 \pm 0.05^{*}$ & $5.7 \pm 0.10^{*}$ \\
& & & \\
\hline
\end{tabular}

* Significantly different from normal $(P<0.05)$. cepting that the osmolality of early distal fluid as $142 \pm 6$ mosm, and $\mathrm{Cl}$ $\sim 26 \mathrm{mM}$ as reported by Galla et al. (5), $22 \mathrm{mM}$ urea and Lissamine green dye were added to a solution and the analyzed content was determined to contain $30 \mathrm{mM}$ bicarbonate, $64 \mathrm{mM} \mathrm{Na}$, and $2 \mathrm{mM} \mathrm{K}$. In all subsequent protocols, as far as possible, $\mathrm{Na}, \mathrm{K}, \mathrm{Cl}$, and osmolality was held constant with appropriate manipulations of urea and gluconate as Table I shows. Thus, the analyzed bicarbonate varied from 10 to $41 \mathrm{mM}$, while $\mathrm{Na}$ and $\mathrm{K}$ remained at $\sim 64$ and $2 \mathrm{mM}$, respectively.

$\mathrm{CO}_{2}$ equilibration of perfusion solutions. In our recent microperfusion study (4), we equilibrated perfusion solutions by the "indirect" method described by Cogan et al. (8) to attain a pCO $\mathrm{CO}_{2}$ of $\sim 65 \mathrm{mmHg}$. In this procedure, mineral oil is equilibrated with Hepes buffer solution consisting of $100 \mathrm{mM}$ Hepes, $48 \mathrm{mM} \mathrm{NaHCO}_{3}$, and $\mathrm{CO}_{2}$ gas. Thereafter the perfusion solution is left in contact with this mineral oil. All mineral oil with which samples or perfusion solutions were in contact (micropuncture pipettes, perfusion pipettes, microcalorimetry sample tray, etc.) was exposed to the same $\mathrm{CO}_{2}$ equilibrated method. In the present studies, we have taken additional steps to establish an appropriate perfusate $\mathrm{CO}_{2}$ tension. Solutions 9 and 10 (see Table I), were directly gassed using a $10 \% \mathrm{CO}_{2} / 90 \% \mathrm{O}_{2}$ mixture and thereafter, using macro acid-base methods (see below), the $\mathrm{pCO}_{2}$ was determined by direct measurement of $\mathrm{pH}$ and total $\mathrm{CO}_{2}\left(\mathrm{pCO}_{2}=72.0 \pm 1.5 \mathrm{mmHg}, n=17\right)$ of the perfusate solution. Using this method, we gained further confidence that a significant portion of the $\mathrm{tCO}_{2}$ accumulation we observed was not based upon insufficient tonometry of the perfusion solution. Indeed, using a gassed perfusion solution of $10 \mathrm{mM} \mathrm{tCO}, 10$ perfusions at high flow were carried out and these showed accumulation of $\mathrm{tCO}_{2}$ in 9 of 10 cases $\left(\mathrm{JtCO}_{2}=-31 \pm 8\right.$ $\mathrm{pmol} \cdot \mathrm{min}^{-1} \cdot \mathrm{mm}^{-1}$ ) and $\mathrm{JtCO}_{2}$ was significantly different from $0, P$ $<0.05$. These 10 determinations are not shown in results and are distinct from the data shown in Figs. 2 and 3 and Table III. In addition, the experiments conducted to demonstrate bicarbonate entry without an initial gradient (solutions 9 and 10) also involve direct gassing. Thus, Fig. 3 (see Results) shows not only perfusion solutions carefully matched to plasma $\mathrm{tCO}_{2}$ concentration, but also direct tonometry to ensure appropriately high perfusate $\mathrm{CO}_{2}$ tensions.

Ammonia entry studies. To evaluate the possibility that $\mathrm{NH}_{3}$ entered into the lumen and thereby generated bicarbonate, additional studies were carried out on six rats perfused at high flow with the most acidic perfusion solution (solution 6 containing $12 \mathrm{mM} \mathrm{HCO}$ ).

Analytical methods. Measurement of tritiated inulin concentrations, total $\mathrm{CO}_{2}$ by microcalorimetry, $\mathrm{Na}$ and $\mathrm{K}$ by graphite furnace atomic absorption, and calculation of fluxes have all been recently detailed (4). 
In the present experiments, as before, the microperfusion pump was calibrated in vitro in the course of every experiment and quantitative collections were obtained so as to detect significant departures from nominal perfusion rates. The in vivo calculated perfusion rates were $7.1 \pm 0.4 \mathrm{nl} / \mathrm{min}(n=92)$ and $23.7 \pm 0.5 \mathrm{nl} / \mathrm{min}(n=92)$. In the case of the $15 \mathrm{nl} / \mathrm{min}$ perfusion series, $13.6 \pm 0.2 \mathrm{nl} / \mathrm{min}(n=20)$, was measured. A similar small discrepancy between collected and nominal rates has been observed before (9). Ammonia concentration was measured by the method of Cheema-Dhadli et al. which permitted the detection of 0.5 $\mathrm{mM}$ ammonium (10).

Statistical methods. Statistical methods consisted of using linear model procedures to assess the influence of the various contending variables. The response measure of interest i.e., the dependent variable, was $\mathrm{JtCO}_{2}$. Because the purpose of the analyses was to assess differences in $\mathrm{JtCO}_{2}$ across the experimental protocols, e.g., acetazolamide-treated versus normal rats, a basic analysis of variance approach was adopted. However, because there was also a need to control for simultaneous movements of $\mathrm{H}_{2} \mathrm{O}, \mathrm{Na}$, and $\mathrm{K}$, these parameters, centered about their means, were introduced as covariates into the model. Thus, comparisons between protocols consisted of comparing the $\mathrm{JtCO}_{2}$ means, adjusted for these confounding influences. This analysis strategy may be characterized as an analysis of covariance. $F$ tests were performed to test statistical hypotheses in accordance with established statistical practice, and the resulting $P$ values are reported throughout the text and in Table III.

The statistical procedures also took into account the fact that a pair of observations were recorded from each tubule, that is, one at $7 \mathrm{nl} / \mathrm{min}$ (normal flow) and the other at $24 \mathrm{nl} / \mathrm{min}$ (high flow). It would seem reasonable to suppose a priori that the same correlation structure existed between the two observations from the same tubule. This correlation structure was incorporated directly into the statistical model.
A separate analysis was performed to judge the relationship between $\mathrm{JtCO}_{2}$ and the concentration of $\mathrm{tCO}_{2}$ perfused. Here, a regression analysis was performed, with $\mathrm{JtCO}_{2}$ as the dependent variable and the mean tubular fluid total $\mathrm{CO}_{2}$ concentration as the independent variable. The analysis again adjusted for simultaneous movements of $\mathrm{H}_{2} \mathrm{O}, \mathrm{Na}$, and $\mathrm{K}$, and these were introduced as covariates into the model. In addition, since the relationship was expected to be different at the normal flow rate than at the high flow rate, a separate model was provided for each flow. Standard $F$ tests were then performed to assess the significance of the predictor variables. Previous reports from this laboratory $(4,11)$ have also addressed these statistical issues.

\section{Results}

Table II provides blood values on normal rats, alkalotic rats, and rats subject to acetazolamide treatment. In 27 nephrons (eight alkalotic rats) free-flow early distal samples were obtained and provided the following data: single nephron glomerular filtration rate, $31.8 \pm 1.8 \mathrm{nl} / \mathrm{min}$; tubular flow rate, $8.0 \pm 0.6 \mathrm{nl} / \mathrm{min}$; $\left[\mathrm{tCO}_{2}\right], 30.9 \pm 1.7 \mathrm{mM} ;[\mathrm{Na}], 64.8 \pm 3.9 \mathrm{mM}$; and $[\mathrm{K}] 1.6 \pm 0.4$ $\mathrm{mM}$. It is from these values that the composition of solution 3 was designed to simulate endogenous free-flow early distal fluid.

\section{Results from alkalotic rats}

This first series of experiments was designed to detect $\mathrm{tCO}_{2}$ secretion in a setting where it could be expected to be present. Thus, we used alkalotic rats and instituted a high lumen to plasma chloride gradient (3).

Table III. Summary of Microperfusion Data

\begin{tabular}{|c|c|c|c|c|c|c|c|c|c|}
\hline Solution & Protocol & $\frac{\text { No. tubules }}{\text { No. rats }}$ & $\begin{array}{l}\text { Tubular } \\
\text { length }\end{array}$ & $\begin{array}{l}\text { Perfusion } \\
\text { rate }\end{array}$ & $\begin{array}{l}\text { Perfusate } \\
{\left[\mathrm{tCO}_{2}\right] \mathrm{mM}}\end{array}$ & $\begin{array}{l}\text { Collected } \\
{\left[\mathrm{tCO}_{2}\right] \mathrm{mM}}\end{array}$ & $\mathrm{JH}_{2} \mathrm{O}$ & $\mathrm{JtCO}_{2}$ & $\begin{array}{l}\text { p value for } \\
\text { flow effect }\end{array}$ \\
\hline & & & $m m$ & $n l \cdot \min ^{-1}$ & & & $n l \cdot \min ^{-1} \cdot m m^{-1}$ & $\mathrm{pMol} \cdot \mathrm{min}^{-1} \cdot \mathrm{mm}^{-1}$ & \\
\hline 1 & $\begin{array}{l}\text { Alkalotic rats, } 125 \mathrm{mM} \\
\quad \mathrm{Cl}\end{array}$ & $11 / 7$ & $1.69 \pm 0.09$ & 15 & $23.9 \pm 0.4$ & $28.9 \pm 1.0$ & $0.27 \pm 0.2$ & $-28 \pm 6$ & - \\
\hline 2 & $\begin{array}{l}\text { Alkalotic rats, } \mathrm{SO}_{4} \\
\text { substitution for } \mathrm{Cl}\end{array}$ & $9 / 6$ & $1.46 \pm 0.10$ & 15 & $24.0 \pm 0.5$ & $26.8 \pm 0.5$ & $0.20 \pm 0.2$ & $-26 \pm 5$ & - \\
\hline \multirow[t]{2}{*}{3} & Alkalotic rats, simulated & $16 / 10$ & $1.44 \pm 0.07$ & 7 & & $38.8 \pm 1.7$ & $1.35 \pm 0.2$ & $14 \pm 7$ & \\
\hline & tubular fluid & & & 24 & $30.3 \pm 0.2$ & $35.7 \pm 1.0$ & $1.48 \pm 0.2$ & $-36 \pm 15$ & 0.006 \\
\hline \multirow[t]{2}{*}{4} & Normal rats, $\left[\mathrm{tCO}_{2}\right]$ & $7 / 6$ & $1.45 \pm 0.05$ & 7 & & $46.4 \pm 3.9$ & $1.66 \pm 0.3$ & $57 \pm 8$ & \\
\hline & perfusate $>$ plasma & & & 24 & $41.0 \pm 1.0$ & $47.7 \pm 2.6$ & $2.37 \pm 0.7$ & $2 \pm 10$ & 0.037 \\
\hline \multirow[t]{2}{*}{5} & Normal rats, $\left[\mathrm{tCO}_{2}\right]$ & $11 / 7$ & $1.36 \pm 0.07$ & 7 & & $38.8 \pm 2.2$ & $1.72 \pm 0.2$ & $10 \pm 7$ & \\
\hline & perfusate $\approx$ plasma & & & 24 & $27.0 \pm 0.5$ & $32.9 \pm 1.1$ & $2.43 \pm 0.3$ & $-29 \pm 18$ & 0.030 \\
\hline \multirow[t]{2}{*}{6} & Normal rats, $\left[\mathrm{tCO}_{2}\right]$ & $11 / 9$ & $1.45 \pm 0.10$ & 7 & & $17.6 \pm 1.0$ & $1.64 \pm 0.3$ & $-12 \pm 3$ & \\
\hline & perfusate $<$ plasma & & & 24 & $10.3 \pm 0.2$ & $15.0 \pm 0.6$ & $1.65 \pm 0.3$ & $-48 \pm 7$ & 0.002 \\
\hline \multirow[t]{2}{*}{7} & As solution $6+$ systemic & $8 / 4$ & $1.45 \pm 0.09$ & 7 & & $17.9 \pm 2.0$ & $2.76 \pm 0.3$ & $2 \pm 5$ & \\
\hline & $\begin{array}{l}\text { and luminal } \\
\text { acetazolamide }\left(10^{-3}\right. \\
\text { M) blockade }\end{array}$ & & & 24 & $10.9 \pm 0.1$ & $15.7 \pm 0.5$ & $2.70 \pm 0.5$ & $-30 \pm 5$ & 0.140 \\
\hline \multirow[t]{2}{*}{8} & As solution $6+$ amiloride & $9 / 8$ & $1.74 \pm 0.10$ & 7 & & $20.3 \pm 1.0$ & $1.48 \pm 0.2$ & $-11 \pm 2$ & \\
\hline & & & & 24 & $10.8 \pm 0.1$ & $14.4 \pm 0.8$ & $1.72 \pm 0.5$ & $-29 \pm 9$ & 0.041 \\
\hline \multirow[t]{2}{*}{9} & Normal rats perfusate & $10 / 7$ & $1.48 \pm 0.06$ & 7 & & $39.4 \pm 1.6$ & $1.02 \pm 0.2$ & $2 \pm 4$ & \\
\hline & $\begin{array}{l}\text { directly gassed, } \\
\text { perfusate }\left[\mathrm{tCO}_{2}\right] \\
=\text { plasma }\left[\mathrm{tCO}_{2}\right]\end{array}$ & & & 24 & $31.7 \pm 0.2$ & $36.3 \pm 1.2$ & $1.13 \pm 0.3$ & $-33 \pm 12$ & 0.012 \\
\hline \multirow[t]{2}{*}{10} & As solution $3+$ systemic & $12 / 7$ & $1.38 \pm 0.10$ & 7 & & $44.6 \pm 2.6$ & $2.02 \pm 0.2$ & $26 \pm 10$ & \\
\hline & $\begin{array}{l}\text { and luminal }\left(10^{-3} \mathrm{M}\right) \\
\text { acetazolamide } \\
\text { blockade }\end{array}$ & & & 24 & $30.7 \pm 0.3$ & $38.2 \pm 1.5$ & $3.75 \pm 0.7$ & $19 \pm 8$ & 0.542 \\
\hline
\end{tabular}


Fig. 1 shows two sets of experiments on alkalotic rats: perfusion at $15 \mathrm{nl} / \mathrm{min}$ with a $25 \mathrm{mM} \mathrm{tCO}$ solution with and without sulphate substitution for chloride (solutions 1 and 2, Table I). In addition, paired perfusions at 7 and $24 \mathrm{nl} / \mathrm{min}$ with solution 3 were also carried out on these animals. As Fig. 1 and Table III show, in the 15-nl perfusion series, $\mathrm{tCO}_{2}$ secretion occurs and is significantly different from 0 but is not modulated by sulphate substitution for chloride $\left(\mathrm{JtCO}_{2}=-26 \pm 5\right.$ vs. $-28 \pm 6$ $\left.\mathrm{pmol} \cdot \mathrm{min}^{-1} \cdot \mathrm{mm}^{-1}, P>0.05\right)$.

To determine if $\mathrm{tCO}_{2}$ accumulation could occur at normal flow rates and with perfusion fluid composition similar to that found at the early distal tubule site of alkalotic rats, the paired perfusion studies were done. $\mathrm{JtCO}_{2}$ values for perfusion at 7 and $24 \mathrm{nl} / \mathrm{min}$ with solution 3 were $14 \pm 7$ and $-36 \pm 15$ $\mathrm{pmol} \cdot \mathrm{min}^{-1} \cdot \mathrm{mm}^{-1}, P<0.01$ (see also Table III). In addition, multivariate statistical analyses (see Methods) also showed a relationship of $\mathrm{JtCO}_{2}$ to $\mathrm{JK}(P=0.004)$ independent of the expected flow effect on $\mathrm{K}$ secretion. At $7 \mathrm{nl} / \mathrm{min} \mathrm{JK}$ was $-38 \pm 6$ vs. $-89 \pm 10 \mathrm{pmol} \cdot \mathrm{min}^{-1} \cdot \mathrm{mm}^{-1}$ at $24 \mathrm{nl} / \mathrm{min}$. $(P<0.01)$. Corresponding $\mathrm{JNa}$ values were $39 \pm 23$ and $-3 \pm 48 \mathrm{pmol} \cdot$ $\mathrm{min}^{-1} \cdot \mathrm{mm}^{-1}$ at 7 and $24 \mathrm{nl} / \mathrm{min}$, respectively.

\section{Results from normal rats}

Because high flow was associated with $\mathrm{tCO}_{2}$ accumulation in alkalotic rats, we next considered whether normal rats would also show the same response. Further, in these animals we also wished to know if the lumen to plasma $\mathrm{tCO}_{2}$ gradient could modulate this effect.

Perfusion with $10 \mathrm{mM}\left[\mathrm{tCO}_{2}\right]$. Of nine animals studied in this group, five were subject to control dialysis (see Methods) and four were not dialyzed. The $\mathrm{JtCO}_{2}$ values given in Table III and Fig. 2 indicate a highly significant flow effect $(P=0.002)$; $\mathrm{JtCO}_{2}$ was $-12 \pm 3 \mathrm{pmol} \cdot \mathrm{min}^{-1} \cdot \mathrm{mm}^{-1}$ at $7 \mathrm{nl} / \mathrm{min}$ and was $-48 \pm 7 \mathrm{pmol} \cdot \mathrm{min}^{-1} \cdot \mathrm{mm}^{-1}$ at $24 \mathrm{nl} / \mathrm{min}$. The initial perfusate $\mathrm{tCO}_{2}$ concentration of 10.3 rose to $17.6 \mathrm{mM}$ in the normal flow

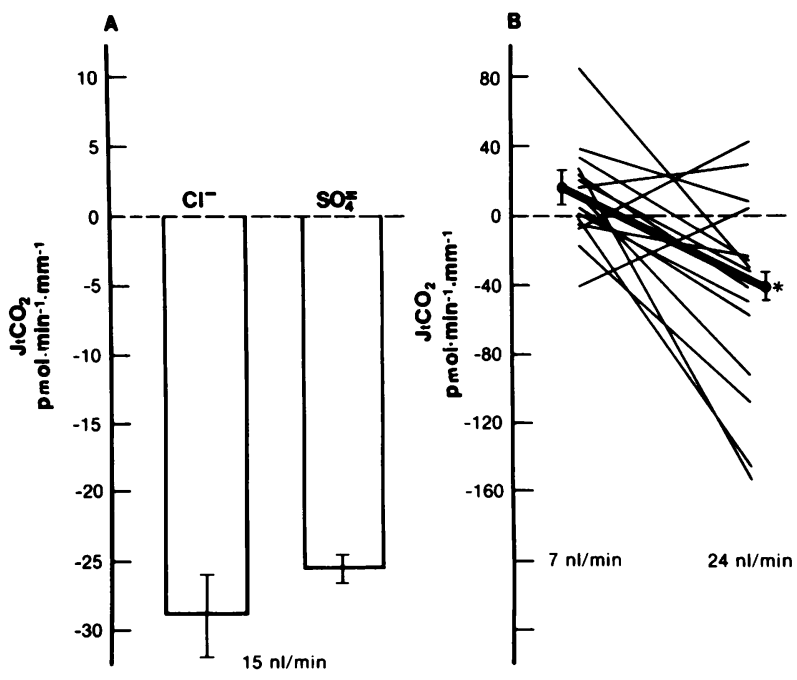

Figure 1. Distal tubule $\mathrm{JtCO}_{2}$ in alkalotic rats. $(A)$ Effect of sulfate substitution for chloride (solutions 1 and 2, Table I). Bars show mean \pm SEM. (B) Effect of increasing flow rate from normal to high flow while perfusing with a simulated endogenous early distal fluid. The bold face line shows the mean $\pm \mathrm{SEM}$ for $\mathrm{JtCO}_{2}$. Lighter lines connect paired data from individual tubules. $P$ values are shown in Table III. group and to $15.0 \mathrm{mM}$ in the high flow group. JK and JNa were $-67 \pm 14$ and $15 \pm 32 \mathrm{pmol} \cdot \mathrm{min}^{-1} \cdot \mathrm{mm}^{-1}$ at normal flow and $-122 \pm 24$, and $-69 \pm 60 \mathrm{pmol} \cdot \mathrm{min}^{-1} \cdot \mathrm{mm}^{-1}$ at the high flow rate, respectively.

Perfusion with $27 \mathrm{mM}\left[t \mathrm{CO}_{2}\right] .11$ tubules (from seven rats) were perfused in this group. Mean $\mathrm{JtCO}_{2}$ was $10 \pm 7$ at normal flow falling to $-29 \pm 18 \mathrm{pmol} \cdot \mathrm{min}^{-1} \cdot \mathrm{mm}^{-1}$ at high flow $(P$ $=0.030$ ) while $\left[\mathrm{tCO}_{2}\right]$ during high flow rose from $27.0 \pm 0.49$ to $32.9 \pm 1.10 \mathrm{mM}$. JK at normal and high flow was $-45 \pm 9$ and $-127 \pm 26 \mathrm{pmol} \cdot \mathrm{min}^{-1} \cdot \mathrm{mm}^{-1}$, respectively. $\mathrm{JNa}$ was $13 \pm 31$ and $101 \pm 63 \mathrm{pmol} \cdot \mathrm{min}^{-1} \cdot \mathrm{mm}^{-1}$ at 7 and $24 \mathrm{nl} / \mathrm{min}$ perfusion rates, respectively.

Perfusion with $41 \mathrm{mM}\left[t \mathrm{CO}_{2}\right]$. Seven tubules were perfused in six rats at 7 and $24 \mathrm{nl} / \mathrm{min}$ as Table III and Fig. 2 show. $\mathrm{JtCO}_{2}$ at normal flow was $57 \pm 8$ and fell to $2 \pm 10 \mathrm{pmol} \cdot \mathrm{min}^{-1} \cdot \mathrm{mm}^{-1}$ at high flow $(P=0.037)$. Initial $\mathrm{tCO}_{2}$ perfusate concentration of $41 \pm 1 \mathrm{mM}$ rose to $46.4 \pm 3.9$ and $47.7 \pm 2.6 \mathrm{mM}$ at normal and high flow, respectively. JK values at normal and high flow were $-32 \pm 6$ and $-71 \pm 28 \mathrm{pmol} \cdot \mathrm{min}^{-1} \cdot \mathrm{mm}^{-1}$, respectively. Corresponding values for $\mathrm{JNa}$ were $37 \pm 37$ and $12 \pm 48 \mathrm{pmol}$. $\mathrm{min}^{-1} \cdot \mathrm{mm}^{-1}$.

Studies designed to evaluate $\mathrm{NH}_{3}$ entry. As noted in Methods, because of the possibility that bicarbonate could be generated by diffusion of $\mathrm{NH}_{3}$ into the lumen and subsequent proton trapping, six perfusions were carried out at high flow using the most acidic solution (solution 6) for measurement of ammonium concentrations. The mean $\mathrm{JtCO}_{2}$ for these perfusions was $-39 \pm 11 \mathrm{pmol} \cdot \mathrm{min}^{-1} \cdot \mathrm{mm}$. Ammonium was not detected in four of these six collections. In the remaining two, values of 1.4 and $0.7 \mathrm{mM}$ were measured. Accordingly, it can be calculated that ammonia entry cannot account for the bicarbonate accumulation rates observed in the various protocols.

Global statistical analyses of data from perfusion in normal rats. Data from three groups of normal rats were submitted to a further combined analyses using the multivariate statistical techniques described in Methods. We attempted to answer: (a) whether there is an overall effect of flow on $\mathrm{JtCO}_{2}$, i.e., in going

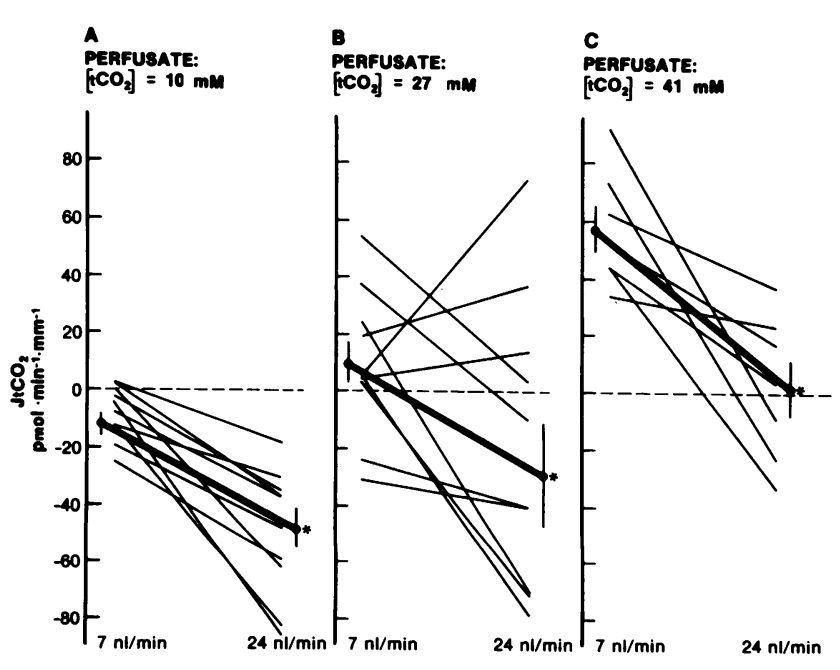

Figure 2. Normal rats: effect of perfusate $\left[\mathrm{tCO}_{2}\right]$ and flow rate on distal tubule $\mathrm{JtCO}_{2}$. The bold face lines connect mean $\pm \mathrm{SEM}$, while lighter lines connect paired data from individual tubules. Perfusion of distal tubules at normal and high flow rates with $(A)$ perfusate $\left[\mathrm{tCO}_{2}\right]$ $=10 \mathrm{mM},(B)$ perfusate $\left[\mathrm{tCO}_{2}\right]=27 \mathrm{mM},(C)$ perfusate $\left[\mathrm{tCO}_{2}\right]=41$ $\mathrm{mM}$. See also Tables I and III. 
from normal to high flow; $(b)$ whether there is an overall effect of perfusate $\mathrm{tCO}_{2}$ concentration on $\mathrm{JtCO}_{2}$ (i.e., in perfusing with $10,27,41 \mathrm{mM} \mathrm{tCO}$ ); and (c) whether there is a significant association between the $\mathrm{tCO}_{2}$ accumulation $\left(-\mathrm{JtCO}_{2}\right)$ and mean tubular fluid $\mathrm{tCO}_{2}$ concentration that could reflect the presence of accumulation at high flow but not at normal flow.

To answer the first question, we have used the multivariate statistical approach to identify and account for confounding influences of other fluxes $\left(\mathrm{JH}_{2} \mathrm{O}, \mathrm{JNa}\right.$, and $\left.\mathrm{JK}\right)$ on $\mathrm{JtCO}_{2}$ as well as the influence of changing perfusate composition. When this is done, a significant change in $\mathrm{JtCO}_{2}(P<0.001)$ is still present in going from normal to high flow. This influence on $\mathrm{JtCO}_{2}$ of flow is also intuitively appreciated by observing the downward slope of the lines in the figures.

To answer whether $\mathrm{JtCO}_{2}$ is significantly associated with perfusate $\mathrm{tCO}_{2}$ concentration, again the simultaneous effects of $\mathrm{JH}_{2} \mathrm{O}, \mathrm{JNa}$, and $\mathrm{JK}$ as well as flow are accounted for. When this is done, a highly significant association $(P<0.0001)$ emerges: i.e., changing perfusate $\mathrm{tCO}_{2}$ concentration from 10 to $41 \mathrm{mM}$ (Figs. 2 and 5) is associated with a striking increase in $\mathrm{JtCO}_{2}$ values.

To address whether the $\mathrm{tCO}_{2}$ accumulation observed at high flow can be shown to be related to luminal tubular fluid $\mathrm{tCO}_{2}$ concentrations, regression analyses were done. These analyses allowed us to determine what the mean tubular fluid concentration should be when the $\mathrm{JtCO}_{2}$ becomes zero at normal and high flow. At normal flow rates, $\mathrm{JtCO}_{2}$ is predicted to be zero when the mean tubular fluid $\mathrm{tCO}_{2}$ concentration rises above 19 mM. At high flow, the mean tubular fluid $\mathrm{tCO}_{2}$ concentration is predicted to be $43 \mathrm{mM}$ when $\mathrm{JtCO}_{2}$ is zero. In other words, high flow is associated with a limiting $\mathrm{tCO}_{2}$ concentration gradient that is more than twice that predicted to be associated with normal flow. This is consistent with the notion of a dissipative flow effect on $\mathrm{tCO}_{2}$ secretion as proposed in the Discussion.

Perfusion with $31 \mathrm{mM}\left[\mathrm{tCO}_{2}\right]$ with and without acetazolamide. 10 tubules were perfused in seven rats with a $\mathrm{tCO}_{2}$ solution that had been directly gassed with $\mathrm{CO}_{2}$ (see Methods). The purpose of this series of experiments was to determine whether $\mathrm{tCO}_{2}$ entry could be elicited in the presence of careful matching of initial perfusion $\mathrm{tCO}_{2}$ concentration with plasma and whether acetazolamide could suppress $\mathrm{tCO}_{2}$ secretion. Fig. 3 and Table III show significant $\mathrm{tCO}_{2}$ accumulation occurred at high flow $(P=0.012)$. Associated with this net $\mathrm{tCO}_{2}$ accumulation, the initial perfusate $\mathrm{tCO}_{2}$ concentration of $31 \mathrm{mM}$ increased in 8 of 10 instances to a mean value of $36.3 \pm 1.2 \mathrm{mM}$ (see Fig. 3 and Table III). That is, net accumulation continued while luminal $\mathrm{tCO}_{2}$ concentrations rose above plasma. Fig. 3 also shows the results of perfusion in the presence of acetazolamide (solution 10). $\mathrm{JtCO}_{2}$ at normal flow was $26 \pm 10$ $\mathrm{pmol} \cdot \mathrm{min}^{-1} \cdot \mathrm{mm}^{-1}$ and was not significantly different from the high flow value of $19 \pm 8 \mathrm{pmol} \cdot \mathrm{min}^{-1} \cdot \mathrm{mm}^{-1}(P>0.05)$. These positive values were significantly different from 0 . Thus, acetazolamide not only blocked the flow effect but prevented net accumulation.

\section{Other results from acetazolamide and amiloride experiments}

These experiments were undertaken to determine if acetazolamide could prevent $\mathrm{tCO}_{2}$ entry even when perfusate $\mathrm{tCO}_{2}$ concentration was much lower than plasma. Further, we also wished to know if in our experimental setting, amiloride could enhance $\mathrm{tCO}_{2}$ secretion as has been reported (2). Fig. 4 shows experiments

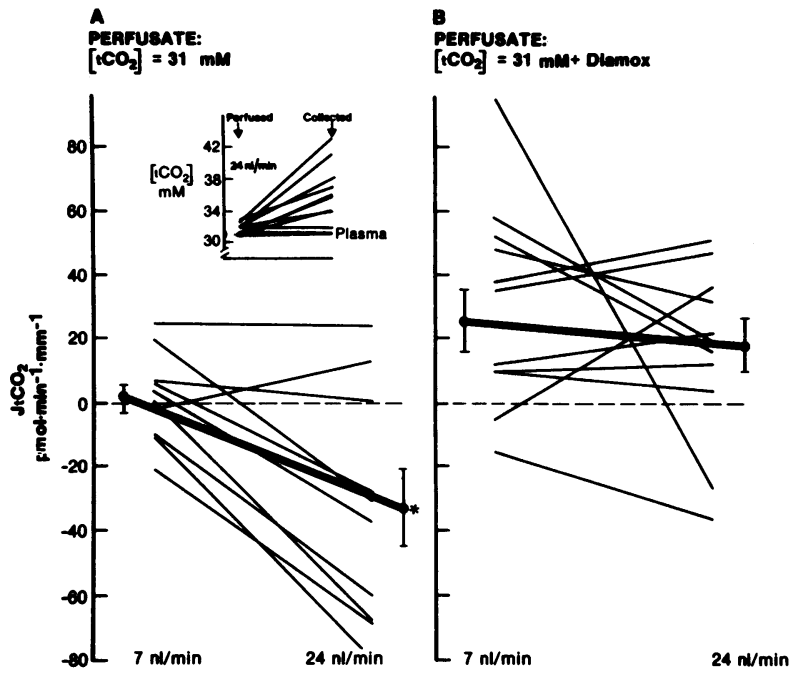

Figure 3. Effects on distal tubule $\mathrm{JtCO}_{2}$ of perfusion with $31 \mathrm{mM}$ $\mathrm{tCO}_{2}$ with and without acetazolamide (Diamox) blockade (solutions 9 and 10$)$. Perfusate $\left[\mathrm{tCO}_{2}\right]$ matched plasma $\left[\mathrm{tCO}_{2}\right] .(A) \mathrm{JtCO}_{2}$ values without acetazolamide (Diamox) (solution 9). Insert shows $\left[\mathrm{tCO}_{2}\right]$ of collected perfusate rises above mean plasma value of $31 \mathrm{mM}$. (See also Results.) (B) $\mathrm{JtCO}_{2}$ values with acetazolamide (Diamox) blockade. Bold face lines connect the $\mathrm{JtCO}_{2}$ mean \pm SEM at each flow rate. Lighter lines connect individual paired data. See Table III.

carried out with $10 \mathrm{mM} \mathrm{tCO}_{2}$ perfusate (Fig. $4 \mathrm{~A}$ ), $10 \mathrm{mM} \mathrm{tCO}_{2}$ perfusate plus acetazolamide treatment (Fig. $4 B$ ), and $10 \mathrm{mM}$ $\mathrm{tCO}_{2}$ perfusate plus amiloride (Fig. $4 \mathrm{C}$ ). As Fig. 4 and Table III show, a significant flow effect persists with amiloride addition to the perfusate. Amiloride did not enhance the rate of total $\mathrm{CO}_{2}$ accumulation. Acetazolamide treatment is not associated with a significant flow effect $(P=0.14)$ when adjusted for covariates if the model includes the $31 \mathrm{mM} \mathrm{tCO}_{2}$ plus acetazolamide perfusions (see above). However, when the $10 \mathrm{mM}$ perfusions with acetazolamide are considered in isolation of the other acetazolamide experiments, a significant flow effect is present $(P=0.005)$. We believe the more appropriate analysis

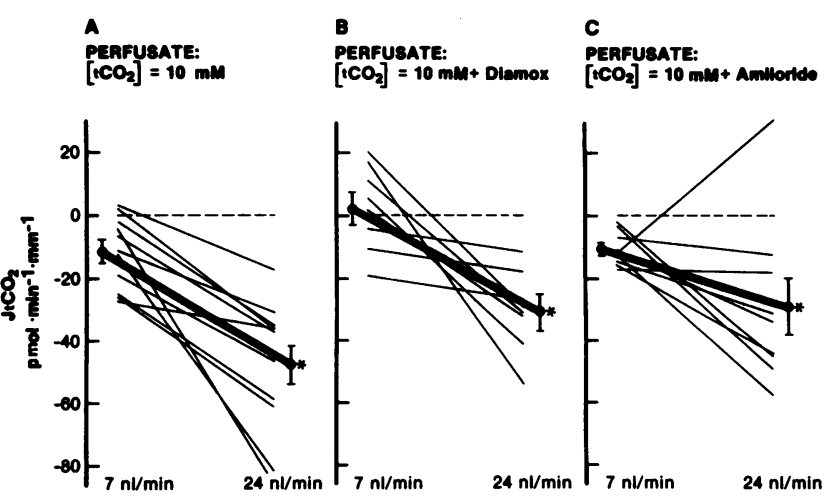

Figure 4. Effects of acetazolamide (Diamox) blockade and amiloride on distal tubule $\mathrm{JtCO}_{2}$. (A) Tubules perfused with $10 \mathrm{mM} \mathrm{tCO}$ (solution 6) at low and high flow, from normal rats. $(B)$ Tubules perfused with $10 \mathrm{mM} \mathrm{tCO}_{2}$ and subjected to luminal (solution 7) and peritubular blockade with acetazolamide (Diamox). $(C)$ Tubules perfused with $10 \mathrm{mM} \mathrm{tCO}$ and amiloride (solution 8) in normal rats. The bold face lines represent the mean \pm SEM. Lighter lines connect paired data from individual tubules. See also Tables I and III. 
is the former. Accordingly, acetazolamide abolishes the flow effect even when a gradient is present.

\section{Discussion}

Recently, it has been shown in vitro that collecting ducts can secrete bicarbonate after alkali feeding (1). Collecting duct bicarbonate movements have also been shown to be inhibited by acetazolamide in vitro (2) and a high lumen to bath $\mathrm{Cl}$ gradient has been noted to favour bicarbonate secretion (3). In the present investigations, we demonstrate net bicarbonate accumulation in superficial distal tubules in vivo in a variety of microperfusion situations. This occurs in both alkalotic and normal rats, but only at high flow. It is modulated by the luminal bicarbonate concentration and can be inhibited by acetazolamide.

Can these observations of distal tubule bicarbonate accumulation be taken as a demonstration of bicarbonate secretion? As noted in Methods, the perfusion solutions were free of $\mathrm{NH}_{4}^{+}$, phosphate, nonbicarbonate buffers, and other constituents normally found in distal tubule fluid. Careful $\mathrm{CO}_{2}$ equilibration of perfusates prevented $\mathrm{CO}_{2}$ gas entry so that the $\mathrm{tCO}_{2}$ accumulation observed is not attributable to perfusate equilibration in situ by the peritubular gas tension. On the other hand, entry of $\mathrm{NH}_{3}$ gas is theoretically possible and could therefore generate $\mathrm{HCO}_{3}$ by acting as a luminal proton acceptor. However, as noted in Results, separate studies showed that $\mathrm{NH}_{4}^{+}$concentrations were insufficient to account for the $\mathrm{tCO}_{2}$ accumulation. Finally, it is conceivable that the absence of tubular fluid constituents normally found at the distal tubule site during free-flow could impede a unidirectional $\mathrm{HCO}_{3}$ (reabsorptive) flux that may be present. Were this so, a secretory component could be unmasked. Indeed, it is possible that differences between perfusion solutions and free-flow tubular fluid account for $\mathrm{HCO}_{3}$ reabsorption reported recently in free flow (12) but not in microperfusion studies $(4,6)$.

Statistical methods. We have previously drawn attention, at some length to statistical approaches appropriate for micropuncture studies in which several variables are measured simultaneously $(4,11)$. In the present study we have used approaches similar to those reported very recently (4) and, accordingly, we will not detail the arguments here. Briefly, we have undertaken multivariate statistical analyses which separate out effects on $\mathrm{JtCO}_{2}$ which may be caused by simultaneous movements of $\mathrm{H}_{2} \mathrm{O}, \mathrm{Na}$, and $\mathrm{K}$, in addition to flow effects and the different perfusion or inhibitor protocols employed. The results presented, therefore, are explicit with regard to assignment of, say, a flow effect on $\mathrm{JtCO}_{2}$. Thus, in a given experimental setting even though $\mathrm{JtCO}_{2}$ may be shown to be influenced by (or associated with) $\mathrm{H}_{2} \mathrm{O}, \mathrm{Na}$, or $\mathrm{K}$ movements, a flow effect (which is also related to $\mathrm{K}$ movements) may nevertheless be present.

Alkalotic rats. We first examined alkalotic rats because it appeared reasonable, a priori, to demonstrate in vivo bicarbonate secretion during systemic metabolic alkalosis and, at the same

2. Table III reveals that at high flow, $\mathrm{HCO}_{3}$ accumulation rates for alkalotic rats (solution 3 ) are not different from similarly perfused control animals (solution 9), despite a more favourable plasma to lumen $\mathrm{tCO}_{2}$ gradient in the alkalotic group. It is possible that hypokalemia (see Table II) may have impeded $\mathrm{HCO}_{3}$ secretion by collecting duct-type epithelium in our alkalotic rats as has been suggested recently in potassium depleted rabbits (13).

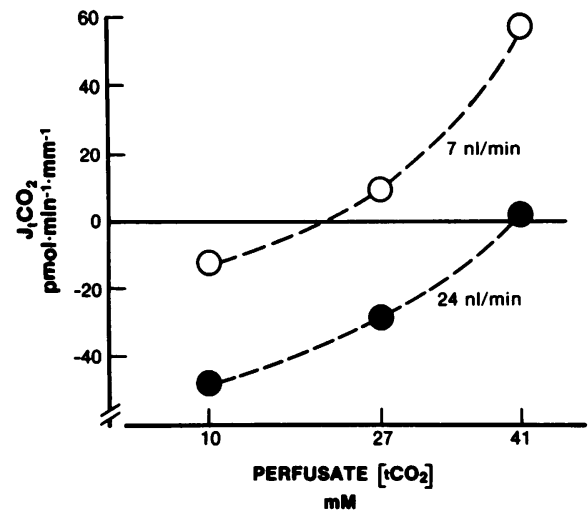

Figure 5. Relationship between distal tubule $\mathrm{JtCO}_{2}$ and perfusate $\left[\mathrm{tCO}_{2}\right]$ at constant flow in normal rats. Mean values for $\mathrm{JtCO}_{2}$ are shown as open or closed circles. Dotted lines were drawn free-hand. Figure depicts data already presented in Fig. 2 and Table III.

time, in the presence of high luminal chloride concentrations. Therefore, solution 1 was constituted so as to reverse the transtubular chloride gradient and to provide a bicarbonate concentration similar to that previously used in microperfusion studies in this and another laboratory $(4,6)$. As already noted, net bicarbonate accumulation occurred and could not be suppressed when sulphate was substituted for chloride in the perfusion solution. In view of these results, we considered whether bicarbonate accumulation could also occur in alkalotic animals when the perfusate was identical to that occurring in vivo with respect to flow rate and composition. Based on the results of in vivo free-flow early distal collections, we constituted such a solution (Table I) and perfused at both 7 and $24 \mathrm{nl} / \mathrm{min}$, i.e., at normal and high flow. The failure of bicarbonate accumulation to occur at normal flow indicated that systemic metabolic alkalosis in these animals was not a sufficient condition to elicit bicarbonate accumulation. However, at high flow, significant accumulation occurred, ${ }^{2}$ therefore requiring experiments on normal rats.

Normal rats. In normal rats distal tubules were perfused with four different total $\mathrm{CO}_{2}$ concentrations as well as with acetazolamide and amiloride. As already noted in Methods, the experiments involving $31 \mathrm{mM} \mathrm{tCO}_{2}$ were undertaken to ensure that initial perfusate $\mathrm{tCO}_{2}$ concentrations exactly matched those of plasma and that perfusate $\mathrm{pCO}_{2}$ was appropriate. The results of these perfusions in normal animals (Figs. 2-5) indicate unequivocally that perfusate $\mathrm{tCO}_{2}$ concentration and flow have significant effects on $\mathrm{tCO}_{2}$ accumulation. Thus, low flow and high perfusion $\mathrm{tCO}_{2}$ concentrations separately suppress $\mathrm{tCO}_{2}$ accumulation as seen in Fig. 5. When the perfusate $\mathrm{tCO}_{2}$ concentration is $31 \mathrm{mM}$, i.e., when there is no initial plasma to lumen gradient, increasing flow from 7 to $24 \mathrm{nl} / \mathrm{min}$ elicits brisk secretion (Fig. 3). Thus, it appears, that $\mathrm{tCO}_{2}$ accumulation can proceed against an electrochemical gradient insofar as the distal tubule is associated with a negative transtubular potential difference. As Fig. 3 shows, the perfusate concentration in association with net $\mathrm{tCO}_{2}$ accumulation rises to exceed the plasma by 6-8 mM.

Effects of acetazolamide and amiloride. Previous work has established the sensitivity of both proton secretion and bicarbonate secretion in reptilian epithelia to acetazolamide inhibition. Indeed, bicarbonate secretion in rabbit cortical collecting ducts was demonstrated by McKinney and Burg to be inhibited 
by acetazolamide and enhanced by amiloride (2). This infers that amiloride inhibition could enhance bicarbonate secretion by impeding a bicarbonate reabsorptive counterflux and that acetazolamide would inhibit bicarbonate secretion by blocking the carbonic anhydrase (C.A.)-sensitive reaction: $\mathrm{OH}^{-}+\mathrm{CO}_{2}$ $\stackrel{\text { C.A. }}{\rightarrow} \mathrm{HCO}_{3}^{-}$. In this view, hydroxyl ions are released into the cell cytoplasm, presumably by proton secretion at the antiluminal membrane. Fromter and associates have demonstrated in rat proximal tubules, that acetazolamide blocks bicarbonate exit from the cell by inhibiting the above reaction or some equivalent process $(14,15)$. Because our results show that acetazolamide treatment can suppress $\mathrm{tCO}_{2}$ accumulation, it is possible that distal tubule $\mathrm{tCO}_{2}$ secretion is also carbonic anhydrase dependent. That amiloride did not enhance $\mathrm{tCO}_{2}$ accumulation in our studies could imply that there was no proton secretory flux (which would reabsorb $\mathrm{HCO}_{3}$ ) in our $\mathrm{HCO}_{3}$-secreting distal tubules. This would be consistent with our previous microperfusion observations that distal tubules of normal rats do not reabsorb bicarbonate (4).

Flow effect. We now turn to a consideration of how increasing flow can elicit $\mathrm{tCO}_{2}$ accumulation even in the absence of a transtubular $\mathrm{tCO}_{2}$ gradient. For us, the most accessible explanation is provided by the notion of a dissipative flow effect as offered by Wright (16) to explain entry of potassium in distal tubules at high flow. According to this view, the larger fluid volume presented to a secreting luminal epithelium will tend to reduce the concentration achieved by the secreted substance and thereby prevent the attainment of a limiting concentration gradient. We recognize, of course, that unlike potassium, intracellular bicarbonate concentration is almost certainly very low (17) and its existence as an immutable ion in the cytoplasm is unclear. To evaluate this possibility, we have analyzed our data to reveal changes in $\mathrm{JtCO}_{2}$ as a function of mean luminal total $\mathrm{CO}_{2}$ concentrations (see Results). As already noted, high flow is associated with a limiting total $\mathrm{CO}_{2}$ concentration that is much higher than that predicted to be associated with normal flow.

What transport mechanism could underlie this association of higher limiting total $\mathrm{CO}_{2}$ concentrations at high flow versus normal flow? We know of no experimental basis for presuming that high flow or increased intratubular pressure could diminish active proton pumping. In fact, stretch has been recently reported to favour the insertion of cytoplasmic vesicles in the total bladder thereby facilitating the establishment of $\mathrm{Na}$ channels (18). If this analogy is extended to proton pumping, it would support the notion of enhanced rather than diminished hydrogen ion secretion at high flow. In fact, for the proximal tubule (19), it has been noted that flow increase, per se, favors bicarbonate reabsorption, possibly by disrupting limiting radial hydrogen ion gradients. However, assuming there are intercalated cells that do secrete bicarbonate, high flow, by mitigating the rise in intraluminal bicarbonate concentration could favor continued secretion. This could occur by the dissipation by high flow of an alkaline boundary layer-constituted by accumulation of $\mathrm{HCO}_{3}$ or $\mathrm{OH}$ ions-and would favor continuing bicarbonate secretion. Similarly, if stretch could induce insertion of " $\mathrm{HCO}_{3}$ channels" into the luminal membrane, this would also favor secretion and be consistent with our data. These considerations, obviously, are entirely conjectural.

Is it possible that high flow is associated with a more favorable electrochemical gradient or with alterations of delivery rates of co-transported ions? The recent important report of Star et al. (20) indicates that bicarbonate secretion by cortical collecting tubules of desoxycorticosterone acetate (DOCA) ${ }^{3}$-treated rabbits is active, electroneutral, and is closely coupled to $\mathrm{Cl}$ movements. In our studies neither $\mathrm{Cl}$ movements nor transtubular potential differences were measured. Therefore, we are unable to determine if bicarbonate accumulation was modulated by changes in transtubular potential difference or to what extent there may be $\mathrm{Cl}-\mathrm{HCO}_{3}$ coupling. In our experiments in alkalotic rats, where sulphate was substituted for chloride, bicarbonate accumulation was not impeded. This suggests that the rat distal tubule may differ from the rabbit cortical collecting tubule where bicarbonate secretion is inhibited by low luminal chloride concentrations (3), or, alternatively, sufficient chloride may have diffused into the lumen to support $\mathrm{Cl}-\mathrm{HCO}_{3}$ exchange. It is also conceivable that if two intercalated cell types exist in rat distal tubules, they may have different transport features with respect to anion exchange, "polarity" of $\mathrm{H}$ or $\mathrm{HCO}_{3}$ secretion (21), or response to flow. However, that bicarbonate accumulation can proceed against a chemical concentration gradient (see Fig. 3) and that acetazolamide can inhibit this secretion, is in complete accord with the early report of McKinney and Burg (2), and with the current notion that bicarbonate secretion is active (20).

The present data imply that bicarbonate secretion may take place in vivo at high free-flow rates. It is of interest, therefore, to speculate under what circumstances this could occur in vivo and what its significance could be. It is well recognized that potassium secretion occurs at high flow (9) and recently it has been reported that net addition of $\mathrm{NH}_{4}^{+}$can also occur in distal tubules at high flow (22). The simultaneous addition of bicarbonate under such circumstances would, of course, tend to conserve $\mathrm{Cl}$ and also would offset the tendency to alkalosis that might be engendered by enhanced $\mathrm{NH}_{4}^{+}$secretion. Indeed, the recent suggestion of Garcia-Austt et al. (23) that cortical collecting tubule bicarbonate secretion stimulated by DOCA is a regulatory mechanism offsetting brisk medullary collecting duct proton secretion, is consistent with this notion: metabolic alkalosis associated with volume expansion and high tubular flow rates (i.e. $\mathrm{NaHCO}_{3}$ loading and DOCA administration) could be mitigated with high flow, signalling enhanced $\mathrm{HCO}_{3}$ excretion.

In summary, we have undertaken studies designed to examine bicarbonate secretion in distal tubules in vivo. We have shown under a wide variety of microperfusion situations that high flow is associated with $\mathrm{tCO}_{2}$ accumulation in the distal tubule lumen. The rate of $\mathrm{tCO}_{2}$ accumulation is modulated by altering the perfusate $\mathrm{tCO}_{2}$ concentration. However, accumulation still occurs when initial perfusate $\mathrm{tCO}_{2}$ concentration is equal to that of plasma, and indeed, persists in the face of rising luminal $\mathrm{tCO}_{2}$ concentrations. We propose that high flow favors $\mathrm{tCO}_{2}$ accumulation by impeding the attainment of a limiting concentration gradient. Results of acetazolamide inhibition suggest that $\mathrm{tCO}_{2}$ addition to the distal tubular lumen proceeds by a carbonic anhydrase-sensitive process which allows addition of $\mathrm{tCO}_{2}$ into the lumen against an electrochemical gradient. We have recognized that the absence of nonbicarbonate buffers and other constituents found normally in distal tubule fluid could have influenced our results: if a reabsorptive bicarbonate flux depends on such constituents, then their absence could unmask a secretory flux. Accepting this limitation, we conclude that these microperfusion results are consistent with flow-mediated bicarbonate secretion in rat distal tubules in vivo.

3. Abbreviation used in this paper: DOCA, desoxycoricosterone acetate. 


\section{Acknowledgments}

We are grateful to Dr. Mitchell L. Halperin and Surinder Cheema-Dhadli for the ammonia measurements. It is a pleasure to express our appreciation to Mrs. P. Morrissey for her devoted secretarial assistance.

This work was supported by grants from the Medical Research Council and the Kidney Foundation of Canada.

\section{References}

1. McKinney, T. D., and M. B. Burg. 1977. Bicarbonate transport by rabbit cortical collecting tubules. J. Clin. Invest. 60:766-768.

2. McKinney, T. D., and M. B. Burg. 1978. Bicarbonate secretion by rabbit cortical collecting tubules in vitro. J. Clin. Invest. 61:14211427.

3. Laski, M. E., D. G. Warnock, and F. C. Rector, Jr. 1983. Effects of chloride gradients on total $\mathrm{CO}_{2}$ flux in the rabbit cortical collecting tubule. Am. J. Physiol. 244:F112-F121.

4. Levine, D. Z. 1985. An in vivo microperfusion study of distal tubule bicarbonate reabsorption in normal and ammonium chloride rats. J. Clin. Invest. 75:588-595.

5. Galla, J. H., D. N. Bonduris, S. L. Dumbauld, and R. G. Luke. 1984. Segmental chloride and fluid handling during correction of chloridedepletion alkalosis without volume expansion in the rat. J. Clin. Invest. 73:96-106.

6. Lucci, M. S., L. R. Pucacco, N. W. Carter, and T. D. DuBose, Jr. 1982. Evaluation of bicarbonate transport in rat distal tubule: effects of acid-base status. Am. J. Physiol. 243:F335-F341.

7. Levine, D. Z., M. K. Byers, R. A. McLeod, and J. A. Luisello. 1979. Loop of Henle bicarbonate accumulation in vivo in the rat. $J$. Clin. Invest. 63:59-66.

8. Cogan, M. G., D. A. Maddox, M. S. Lucci, and F. C. Rector, Jr. 1979. Control of proximal bicarbonate reabsorption in normal and acidotic rats. J. Clin. Invest. 64:1168-1180.

9. Good, D. W., and F. S. Wright. 1979. Luminal influences on potassium secretion: sodium concentration and fluid flow rate. Am. $J$. Physiol. 236:F192-F205.

10. Cheema-Dhadli, S., R. Hamat, H. Sonnenberg, and M. Halperin. 1981. A micromethod to measure ammonia. Kidney Int. 19:80-82.
11. Raman, S., G. Mousseau, and D. Z. Levine. 1977. Statistical models for renal micropuncture studies. Am. J. Physiol. 233:F349-F357.

12. Capasso, G., U. Guckian, P. Jaeger, G. Malnic, and G. Giebisch. 1986. Bicarbonate reabsorption across the distal tubule is load-dependent. Kidney Int: 29:365A(Abstr.)

13. Hayes, S. R., D. W. Seldin, J. P. Kokko, and H. R. Jacobsen. 1985. Effect of $\mathrm{K}$ depletion on $\mathrm{HCO}_{3}$ transport across rabbit collecting duct segments. Kidney Int. 29:368A. (Abstr.)

14. Burckhardt, B.-C., K. Sato, and E. Fromter. 1984. Electrophysiological analysis of bicarbonate permeation across the peritubular cell membrane of rat kidney proximal tubule. I. Basic observations. Pflugers Arch. 401:34-42.

15. Burckhardt, B.-C., A. C. Cassola, and E. Fromter. 1984. Electrophysiological analysis of bicarbonate permeation across the peritubular cell membrane of rat kidney proximal tubule. II. Exclusion of $\mathrm{HCO}_{3}$ effects on other ion permeabilities and of coupled electroneutral $\mathrm{HCO}_{3}$ transport. Pflugers Arch. 401:43-51.

16. Wright, F. S. 1982. Flow-dependent transport processes: filtration, absorption, secretion. Am. J. Physiol. 243:F1-F11.

17. Yoshitomi, K., and E. Fromter. 1984. Cell pH of rat proximal tubule in vivo and the conductive nature of peritubular $\mathrm{HCO}_{3}\left(\mathrm{OH}^{-}\right)$ exit. Pflugers Arch. 402:300-305.

18. Lewis, S. A., and J. L. C. de Moura. 1982. Incorporation of cytoplasmic vesicles into apical membrane of mammalian urinary bladder epithelium. Nature (Lond.). 297:685-688.

19. Cogan, M. G., and R. J. Alpern. 1984. Regulation of proximal bicarbonate reabsorption. Am. J. Physiol. 247:F387-F395.

20. Star, R. A., M. B. Burg, and M. A. Knepper. 1985. Bicarbonate secretion and chloride absorption by rabbit cortical collecting ducts. $J$. Clin. Invest. 76:1123-1130.

21. Schwartz, G. J., and Q. Al-Awqati. 1985. Polarity of $\mathrm{H}^{+}$transport in the two types of mitochondria-rich (MR) cells of cortical collecting tubules (CCT). Clin. Res. 33:497A(Abstr.)

22. Wilcox, C. S., F. Granges, G. Kirk, D. Gordon, and G. Giebisch. 1984. Effects of saline infusion on titratable acid generation and ammonia secretion. Am. J. Physiol. 247:F506-F519.

23. Garcia-Austt, J., D. W. Good, M. B. Burg, and M. A. Knepper. 1985. Deoxycorticosterone-stimulated bicarbonate secretion in rabbit cortical collecting ducts: effects of luminal chloride removal and in vivo acid loading. Am. J. Physiol. 18:F205-212. 